\title{
Wind Power Plant Voltage Control Optimization with Embedded Application of Wind
} Turbines and Statcom

\author{
Wu, Qiuwei; Solanas, Jose Ignacio Busca; Zhao, Haoran; Kocewiak, Lukasz Hubert
}

Published in:

Proceedings of the 2016 Asian Conference on Energy, Power and Transportation Electrification

Link to article, DOI:

10.1109/ACEPT.2016.7811534

Publication date:

2017

Document Version

Peer reviewed version

Link back to DTU Orbit

Citation (APA):

Wu, Q., Solanas, J. I. B., Zhao, H., \& Kocewiak, L. H. (2017). Wind Power Plant Voltage Control Optimization with Embedded Application of Wind Turbines and Statcom. In Proceedings of the 2016 Asian Conference on Energy, Power and Transportation Electrification IEEE. https://doi.org/10.1109/ACEPT.2016.7811534

\section{General rights}

Copyright and moral rights for the publications made accessible in the public portal are retained by the authors and/or other copyright owners and it is a condition of accessing publications that users recognise and abide by the legal requirements associated with these rights.

- Users may download and print one copy of any publication from the public portal for the purpose of private study or research.

- You may not further distribute the material or use it for any profit-making activity or commercial gain

- You may freely distribute the URL identifying the publication in the public portal 


\section{Wind Power Plant Voltage Control Optimization with Embedded Application of Wind Turbines and Statcom}

\author{
Qiuwei Wu, Jose Ignacio Busca Solanas, Haoran Zhao \\ Centre for Electric Power and Energy, Department of \\ Electrical Engineering \\ Technical University of Denmark \\ Kgs. Lyngby, Denmark \\ qw@elektro.dtu.dk, josetxob@hotmail.com, \\ hzhao@elektro.dtu.dk
}

\begin{abstract}
Increasing wind power penetration and the size of wind power plants (WPPs) brings challenges to the operation and control of power systems. Most of WPPs are located far from load centers and the short circuit ratio at the point of common coupling (PCC) is low. The fluctuations of wind power will cause voltage variations. An optimal voltage control scheme for WPPs with STATCOMs is presented in the paper. It ensures that the voltages within the WPPs and at the high voltage side of the WPPs are within the limits and maximizes the dynamic Var reserve of the WPPs. Case studies were conducted with the simplified Anholt offshore WPP and the case study results demonstrate the efficacy of the proposed optimal voltage control scheme.
\end{abstract}

Index Terms-Full scale converter (FSC), optimal voltage control, STATCOM, wind power plant (WPP), wind turbine (WT)

\section{INTRODUCTION}

The growth of wind power has been considerably large, being around $40 \%$ annually in the last ten years. By the end of 2015 , the total installed capacity of wind power was $432 \mathrm{GW}$ as shown in Figure 1 [1]. The top three countries with the highest installed capacity are China, USA and Germany with $145 \mathrm{GW}, 74 \mathrm{GW}$ and $44 \mathrm{GW}$, respectively.

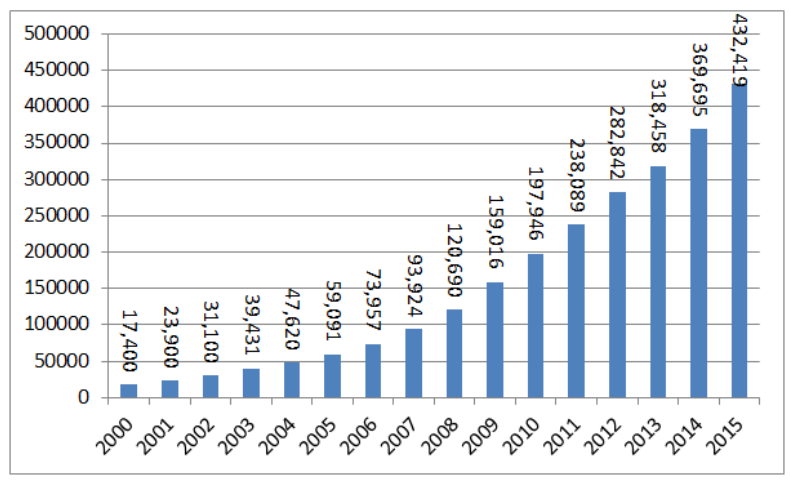

Figure 1. Global cumulative installed capacity of wind power [1]

\author{
Lukasz Hubert Kocewiak \\ DONG Energy Wind Power \\ Gentofte, Denmark \\ lukko@dongenergy.dk
}

The increasing penetration of wind power and growing size of wind farms have a big impact on the system operation and introduce technical challenges to voltage stability [2]. Most large wind power plants (WPPs) are mainly located in areas far from load centers, the Short Circuit Ratio (SCR) at the point of common coupling (PCC) is low [3], and the grid at the connection point is weak. The voltage fluctuation caused by the intermittent power from the WPPs is quite large. Moreover, grid disturbances may cause cascading trip of Wind Turbine Generators (WTGs). Therefore, modern WPPs are required to meet more stringent technical requirements of voltage support specified by system operators. The requirements include reactive power capability of the WPP, voltage operating range at the Point of Connection (POC), voltage control, high- and low- voltage ride through, and frequency control [4].

In order to fulfill these requirements, WPPs have a variety of reactive power (Var) or voltage (Volt) regulation devices: Static Var Compensators (SVCs), Static Var Generators (SVGs), Static Compensator (STATCOM), On Load Tap Changing (OLTC) Transformer, static and controllable shunt reactor, etc. Besides, with the development of power electronics and control technologies, modern WTGs equipped with power electronic converters (Type 3 and Type 4) can control the reactive power, and participate in the voltage control [5].

Several modes of controlling the reactive power of a wind farm have been specified by many grid codes which are defined by transmission system operators for wind power integration, including power factor control, reactive power control and voltage control [6]. For the transmission system, the voltage control mode shows superior performance. This paper focuses on the wind farm control under this mode, i.e. the wind farm controls the voltage at the POC specified by the system operator.

The paper is organized as follows. The optimal voltage control of WPPs is presented in Section II. The case studies are described and discussed in Section III, followed by conclusions. 


\section{OPtimal VolTAGe CONTROL OF WPP}

The optimal voltage control of the WPP is to optimize both the voltage levels of all elements and the reactive power distribution within the WPP. The optimal voltage control of the WPP consists of three modes: corrective voltage control mode, coordinated voltage control mode and preventive voltage control model. The details of the three control modes are described below. The diagram of a WPP is shown in Figure 2.

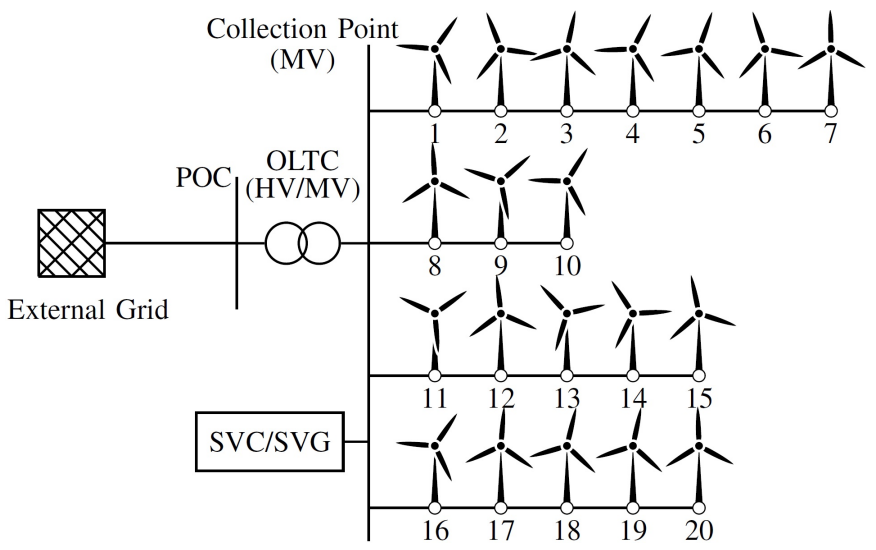

Figure 2. Single line diagram of a WPP

\section{A. Corrective voltage control mode}

The corrective voltage control mode is to ensure that all the WTG bus voltages are within limits. If the WTG bus voltage exceeds the limits, the WPP voltage controller will determine the optimal solutions of reactive power regulation of wind turbine generators and STATCOMs in order to keep the WTG bus voltages within the limits.

The corrective voltage control can be formulated as the optimization problem below.

$$
\begin{gathered}
\min _{\Delta Q_{w t}, \Delta Q_{s}} W_{T}\left\|V_{w t}^{r e a l}-V_{w t}^{n o m}+C_{t w} \Delta Q_{w t}+C_{t s} \Delta Q_{s}\right\|^{2} \\
+W_{w}\left\|\Delta Q_{w t}\right\|^{2}+W_{s}\left\|\Delta Q_{s}\right\|^{2}
\end{gathered}
$$

subject to

$$
\begin{gathered}
V_{w t}^{\min } \leq V_{w t}^{\text {real }}+C_{t w} \Delta Q_{w t}+C_{t s} \Delta Q_{s} \leq V_{w t}^{\max } \\
V_{s}^{\min } \leq V_{s}^{r e a l}+C_{s w} \Delta Q_{w t}+C_{s s} \Delta Q_{s} \leq V_{s}^{\max } \\
V_{w h}^{\min } \leq V_{w h}^{r e a l}+C_{h w} \Delta Q_{w t}+C_{h s} \Delta Q_{s} \leq V_{w h}^{\max } \\
Q_{w t}^{\min } \leq Q_{w t}^{r e a l}+\Delta Q_{w t} \leq Q_{w t}^{\max } \\
Q_{s}^{\min } \leq Q_{s}^{\text {real }}+\Delta Q_{s} \leq Q_{s}^{\max }
\end{gathered}
$$

where $V_{w t}^{\text {real }}$ is the actual WTG terminal voltage; $V_{w t}^{n o m}$ is the nominal WTG terminal voltage and is $1.0 \mathrm{pu} ; \Delta Q_{w t}$ and $\Delta Q_{s}$ are the Var regulation vectors of the WTGs and STATCOMs; $C_{t w}$ and $C_{t s}$ are the sensitivity matrixes of the WTG terminal voltage $V_{w t}$ with respect to $\Delta Q_{w t}$ and $\Delta Q_{s} ; W_{T}, W_{w}$ and $W_{s}$ are weighting factors; $C_{s w}$ and $C_{s s}$ are the sensitivity matrixes of the STATCOM terminal voltage $V_{s}$ with respect to $\Delta Q_{w t}$ and $\Delta Q_{s} ; C_{h w}$ and $C_{h s}$ are the sensitivity matrixes of the WPP voltage at the high voltage side $V_{w h}$ with respect to $\Delta Q_{w t}$ and $\Delta Q_{s} ; V_{w t}^{\min }, V_{w t}^{\max }, V_{s}^{\min }, V_{s}^{\max }, V_{w h}^{\min }$ and $V_{w h}^{\max }$ are the limits of $V_{w t}, V_{s}$ and $V_{w h} ; Q_{w t}^{\min }, Q_{w t}^{\max }, Q_{s}^{\min }$ and $Q_{s}^{\max }$ are the limits of $Q_{w t}$, and $Q_{s}$.

If $\left\|V_{w t}^{\text {real }}-V_{w t}^{n o m}\right\| \geq V_{w t}^{t h}$, the WPP voltage control will operate in the corrective voltage control mode. $V_{w t}^{t h}$ is the threshold value and is usually set as $0.1 \mathrm{pu}$. In order to make sure that the WTG bus voltage values do not exceed the boundaries, $V_{w t}^{t h}$ is set as $0.07 \mathrm{pu}$ and the voltage limits are [0.93 pu, $1.07 \mathrm{pu}$.

\section{B. Coordinated voltage control mode}

The coordinated voltage control mode is to track the voltage reference at the high voltage (HV) side of the WPP from the system operator and mitigate the voltage fluctuations considering all necessary operation constraints. If all the WTG and STATCOM terminal voltages are within limits, and the voltage deviation at the HV side of the WPP is larger than the threshold value, the WPP voltage control will operate in the coordinated voltage control mode. The threshold of the HV side voltage of the WPP, $V_{w h}^{\text {th }}$, is set as $0.05 \mathrm{pu}$.

The coordinated voltage control can be formulated as the optimization below.

$$
\begin{gathered}
\min _{\Delta Q_{w t}, \Delta Q_{s}} W_{H}\left\|V_{w h}^{r e a l}-V_{w h}^{r e f}+C_{h w} \Delta Q_{w t}+C_{h s} \Delta Q_{s}\right\|^{2} \\
+W_{w}\left\|\Delta Q_{w t}\right\|^{2}+W_{s}\left\|\Delta Q_{s}\right\|^{2}
\end{gathered}
$$

subject to constraints (2)-(6).

\section{Preventive voltage control mode}

The preventive voltage control is to maximize the dynamic Var reserve of STATCOMs and replace the Var output from STATCOMs with the one from WTGs. It is realized by driving the Var output of STATCOMs to the middle. As such, there will be both upward and downward regulation capability.

The preventive voltage control can be formulated as the following optimization.

$$
\min _{\Delta Q_{w t}} W_{s}^{\prime}\left\|Q_{s}+\Delta Q_{s}-\frac{1}{2}\left(Q_{s}^{\max }-Q_{s}^{\min }\right)\right\|^{2}+W_{w}^{\prime}\left\|\Delta Q_{w t}\right\|^{2}
$$

subject to constraints (2)-(6) and

$$
C_{s s} \Delta Q_{s}+C_{s w} \Delta Q_{w t}=0
$$

In the corrective and coordinated control modes, the STATCOMs work with the constant-Q mode. The set-point to 
the STATCOM is $Q_{s}^{r e f}=Q_{s}+\Delta Q_{s}$ and the terminal voltage is bounded by (3). In the preventive control mode, the STATCOMs work in the constant $\mathrm{V}$ mode. The voltage reference of the ith STATCOM is $\left[V_{s, i}^{\min }-\xi, V_{s, i}^{\min }+\xi\right]$ where $\xi$ is a small deviation.

\section{CASE STUdy}

In order to test the efficiency of the proposed WPP voltage control method, case studies were conducted using the simplified Anholt offshore WPP.

\section{A. Test System}

The Anholt offshore WPP in Denmark is situated $15 \mathrm{~km}$ from the shore. The installed capacity is $400 \mathrm{MW}$ and it consists of 111 Siemens 3.6MW-120 WTGs. The WTGs are connected to an offshore substation and divided into three groups. Each of them has 37 WTGs which are radially connected in four feeders to a step-up transformer. The point of connection (POC) is at the low voltage (LV) side of the transformer. In the offshore substation, there are three 140 MVA transformers and each transformer is connected to a group of 37 WTGs. The transformers step up the voltage from $33 \mathrm{kV}$ to $220 \mathrm{kV}$ [7].

The offshore substation is connected to an onshore substation through a $24.5 \mathrm{~km}$ submarine cable. In the onshore substation, a 120 MVAr STATCOM is placed. The onshore substation is connected to another substation through a $58 \mathrm{~km}$ underground cable which is connected to the $400 \mathrm{kV}$ external grid. In this substation, there are two 450 MVA transformers and 4 STATCOMs of 60 MVAr each.

The single line diagram of the Anholt offshore WPP is shown in Figure 3. Each WTG represents one feeder.

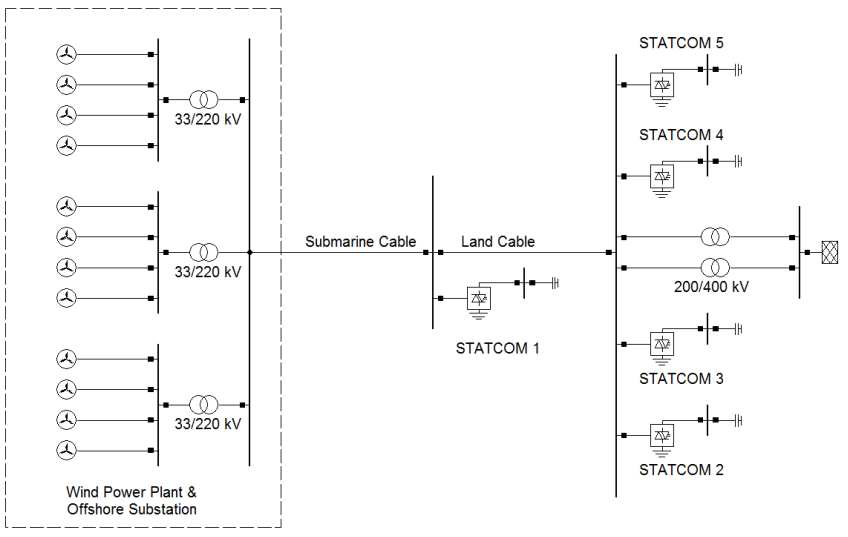

Figure 3. Single line diagram of the Anholt offshore WPP

For testing the proposed WPP optimal voltage control, as long as the system layout is kept, it will not be necessary to include all the details of the Anholt WPP. Therefore, the Anholt WPP is simplified. The simplified WPP consists of 10 WTGs and two STATCOMS. The rest of the system is the same as the Anholt WPP. The simplified WPP is shown in Figure 4. Bus 1 is the bus of the external grid. Bus 12 is the HV side of the WPP main transformer.

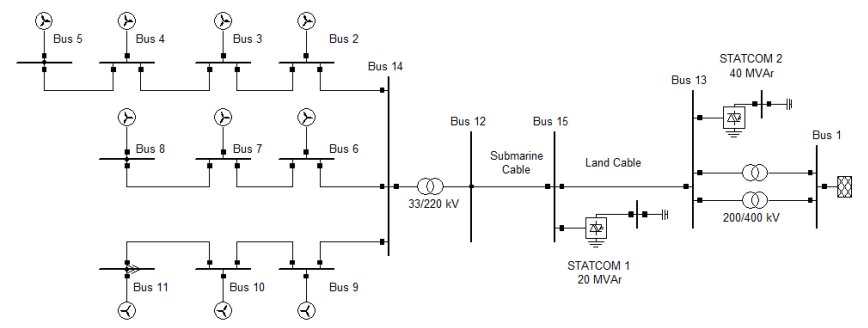

Figure 4. Simplified Anholt Offshore WPP

\section{B. Siemens 3.6 $\mathrm{MW}-120 \mathrm{WTG}$}

The WTGs used in the Anholt offshore WPP is the Siemens 3.6 MW-120 ones. The nominal active power output is $3.6 \mathrm{MW}$ and the diameter is $120 \mathrm{~m}$. The cut-in speed is 3-5 $\mathrm{m} / \mathrm{s}$, the nominal power output is reached with a speed of $12-$ $13 \mathrm{~m} / \mathrm{s}$ and the cut out wind speed is $25 \mathrm{~m} / \mathrm{s}$ [8].

The PQ chart of the Siemens 3.6-120 WTGs is not available from the manufacturer. Therefore, a standard PQ chart of a FSC WTG was used for the case studies. The standard PQ chart is shown in Figure 5. In order to simplify the PQ capability, the squared area is used as the operating range of the reactive power $\mathrm{Q}$ with respect to the active power P. For $1.0 \mathrm{pu}$ active power, the boundaries of the reactive power is $\pm 0.44 \mathrm{pu}$, meaning that the maximum reactive power output is $\pm 1.58 \mathrm{MVAr}$.

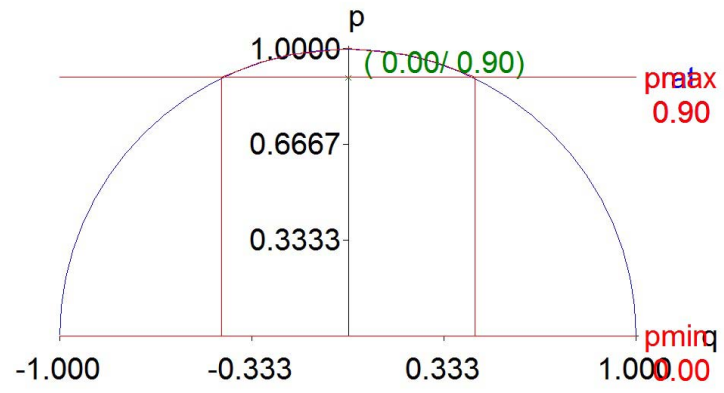

Figure 5. FSC WTG Standard PQ Chart

\section{Case Study Reulsts}

The case study scenarios include low generation, full generation, WTG terminal voltages out of boundary, HV side voltage of the WPP out of boundary, and STATCOM Var output close to full capacity. The results of the three control modes are presented in the following subsections.

\section{1) Corrective voltage control}

For testing the corrective voltage control mode, a case with WTG terminal voltages out of limits was created. The WTG terminal voltages were regulated by the corrective voltage control of the WPP controller to be in the limits. The bus voltages with and without the corrective voltage control are shown in Figure 6. It is shown that the WTG terminal voltages were brought back into the limits with the corrective voltage control. 


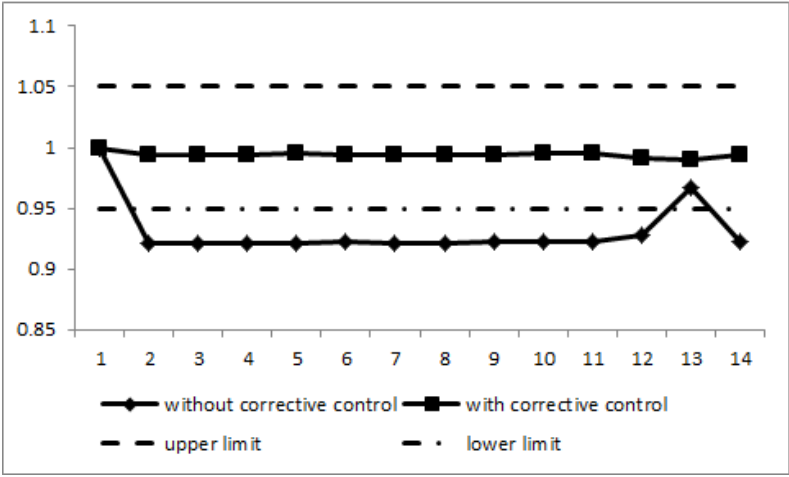

Figure 6. Bus voltages with and without corrective voltage control

\section{2) Coordinated voltage control}

For the coordinated voltage control, the WTG terminal voltages are within the limits. However, the HV side of the WPP main transformer (Bus 1 in Figure 4) is out of the limits. It is shown in Figure 7. With the coordinated voltage control, the HV side voltage of the WPP is within the limits.

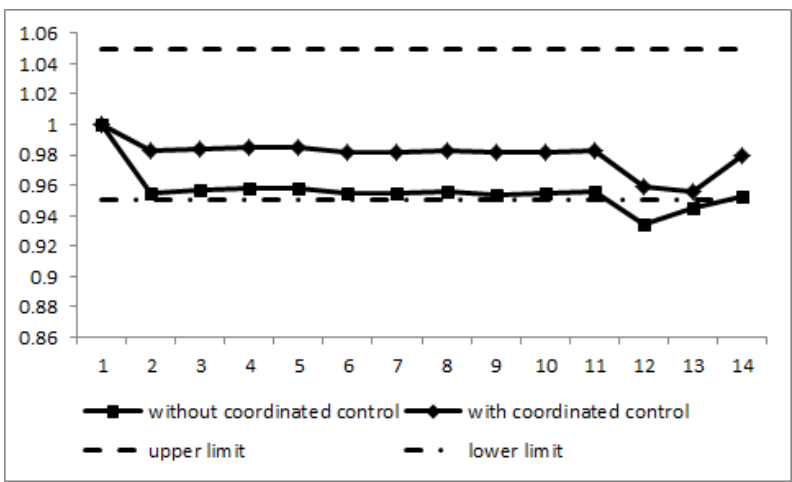

Figure 7. Bus voltages with and without cordinated voltage control

\section{3) Preventive voltage control}

The preventive voltage control is to maximize the dynamic Var reserves and maintain the voltages in the WPP and the external buses. The bus voltages and Var outputs of STATCOMs are shown in Figure 8 and Table I. It is shown that the bus voltages are almost the same. The Var outputs of the STATCOMs are reduced.

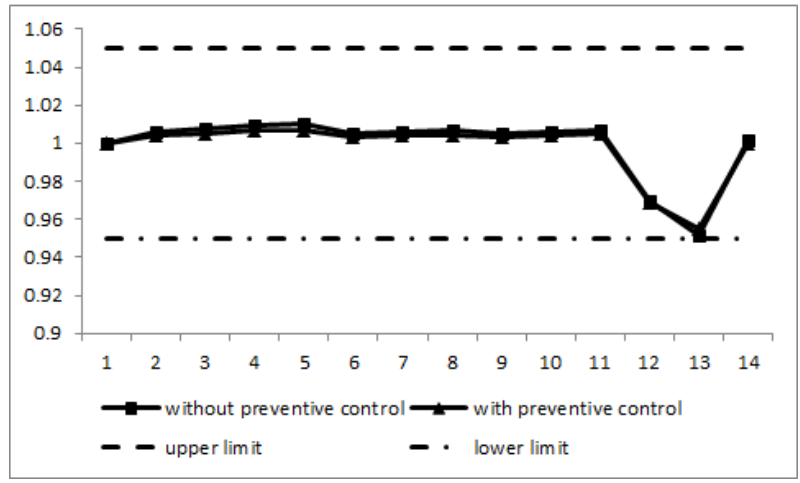

Figure 8. Bus voltages with and without preventive voltage control
TABLE I. VAR OUTPUTS OF THE STATCOMS WITH AND WITHOUT PREVENTIVE VOLTAGE CONTROL

\begin{tabular}{|c|c|c|}
\hline STATCOM & $\begin{array}{c}\text { Var Output without } \\
\text { Preventive Control } \\
\text { (MVar) }\end{array}$ & $\begin{array}{c}\text { Var Output with } \\
\text { Preventive Control } \\
\text { (MVar) }\end{array}$ \\
\hline STATCOM 1 & 12 & 11.4 \\
\hline STATCOM 2 & 20 & 17.64 \\
\hline
\end{tabular}

\section{CONCLUSION}

An optimal voltage control scheme is proposed in this paper for WPPs with STATCOMs. The voltage control is to ensure that the voltages within the WPP and at the HV side of the WPP main transformer are within limits and the dynamic Var reserve is maximized. Case studies results show that the proposed voltage control can determine the optimal Var setpoints of WTGs and STATCOMs to bring the WTG terminal voltages and the HV side voltages of the WPP main transformer back into the limits if there is a voltage violation. When the voltages within the WPP and at the HV side of the WPP main transformer are within limits, the Var outputs of STATCOMs can be reduced to maximize the dynamic Var reserves of the WPP.

\section{REFERENCES}

[1] Global wind energy council, "Global wind statistics 2015", Brussels, Belgium, Feb. 2016. Available: http://www.gwec.net/wpcontent/uploads/vip/GWEC-PRstats-2015 LR.pdf

[2] M. J. Hossain, H. R. Pota, M. A. Mahmud, and R. Ramos, "Investigation of the impacts of large-scale wind power penetration on the angle and voltage stability of power systems," IEEE Syst. Journal, vol. 6 , no. 1, pp. 76-84, 2012.

[3] T. Neumann, C. Feltes, and I. Erlich, "Response of DFG-based wind farms operating on weak grids to voltage sags," in Proc. Power Eng. Soc. Gen. Meeting, 2011, pp. 1-6.

[4] Q. Wu, Z. Xu, and J. Østergaard, "Grid integration issues for large scale wind power plants," in Proc. Power Eng. Soc. Gen. Meeting, 2010, pp. 1-6.

[5] Z. Chen, J. M. Guerrero, and F. Blaabjerg, "A review of the state of the art of power electronics for wind turbines," IEEE Trans. Power Electron., vol. 24, no. 8, pp. 1859-1875, 2009.

[6] J. Fortmann, M. Wilch, F. W. Koch, and I. Erlich, "A novel centralized wind farm controller utilising voltage control capability of wind turbines," in PSCC Power Syst. Comput. Conf., 2008.

[7] Ł. H. Kocewiak, B. L. Øhlenschlæger Kramer, O. Holmstrøm, K. H. Jensen, L. Shuai, "Active Filtering Application in Large Offshore Wind Farms," in Proc. The 13th International Workshop on Large-Scale Integration of Wind Power into Power Systems as well as Transmission Networks for Offshore Wind Farms, Energynautics GmbH, 11-13 November 2014, Berlin, Germany.

[8] Renewable Energy Division Siemens AG Energy Sector. "Siemens Wind Turbine SWT-3.6-120”. 2011 